\title{
Porquê Não Mudam as Famílias? Narrativas de Terapias Familiares de Insucesso
}

\author{
Joana Sequeira ${ }^{1}$ \\ Madalena Alarcão \\ Faculdade de Psicologia e de Ciências da Educação da Universidade de Coimbra, Coimbra, Portugal
}

\section{Resumo}

A terapia familiar sistêmica de enfoque narrativo procura promover a mudança terapêutica através da perturbação das histórias dominantes sobre o problema e da construção de novas histórias para significar os eventos de vida. O objetivo deste estudo consistiu em compreender os aspetos que bloqueiam a mudança narrativa, partindo de uma metodologia de estudo de caso. Para o efeito, foram analisados 2 processos completos de terapia familiar, considerados insucessos por clientes e terapeutas. Foram visualizadas e intensivamente analisadas 16 sessões terapêuticas, através do Sistema de Avaliação da Mudança Narrativa (SAMN). Os resultados mostram que: (a) as narrativas permanecem estáticas, centradas no presente ou no passado, com total ausência de perspectiva de futuro; (b) a família explica as suas dificuldades ou problemas com base em relações diretas de causa-efeito (causalidade linear); (c) a emergência de singularidades e de reflexividade narrativa é pontual, incapaz de perturbar a narrativa dominante e de ser amplificada pelo sistema terapêutico. Com base num modelo de organização da narrativa em três níveis lógicos distintos, as autoras discutem os resultados obtidos realçando a necessidade de identificar e trabalhar o nível em que a narrativa está bloqueada para potenciar a mudança terapêutica ou de $2^{\mathrm{a}}$ ordem.

Palavras-chave: Narrativa, terapia familiar, mudança, insucesso terapêutico.

\section{Why Don't Families Change? Narratives of Family Therapy Failures}

\begin{abstract}
Systemic narrative family therapy promotes change through disruption of the dominant stories about the problem and construction of new stories to signify life events. The aim of this study was to understand the aspects that block the narrative change. In this case study we analyzed two concluded family therapies, considered failures by clients and therapists. Sixteen family therapy sessions were intensively viewed and analyzed through the Assessment System of Narrative Change (SAMN). The results showed that: (a) the narratives remain static, centered in the present or in the past, with total absence of future perspectives, (b) the families explain their problems based on direct relations between causes and effects (linear causality) and (c) the emergence of singularities and narrative reflexivity are punctual and unable to disrupt the dominant narrative and to be amplified by therapeutic system. Based on a model of narrative organization into three distinct logical levels, the authors discuss the results of this study highlighting the need to identify and work on the level where the narrative is blocked to enhance therapeutic change or 2 nd order change.
\end{abstract}

Keywords: Narrative, family therapy, change, therapeutic failure.

1 Endereço para correspondência: Faculdade de Psicologia e de Ciências da Educação, Universidade de Coimbra, Rua do Colégio Novo, Apartado 6153, Coimbra, Portugal 3001-802. E-mail: joanasequeira@esdrm. ipsantarem.pt 


\section{Porqué No Cambian las Familias? Narrativas de Terapias Familiares de Fracaso}

\section{Resumen}

La terapia familiar sistémica, de enfoque narrativo, busca promover el cambio terapéutico a través de la modificación de las historias dominantes sobre el problema y de la construcción de nuevas historias para significar los eventos de la vida. El objetivo de este estudio consistió en comprender los aspectos que bloquean el cambio narrativo, partiendo de una metodología de estudio de caso. Para tal efecto, fueron analizados 2 procesos completos de terapia familiar, considerados fracasos por clientes y terapeutas. Fueron visualizadas e analizadas intensivamente 16 sesiones terapéuticas, a través del Sistema de Evaluación del Cambio Narrativo (SACN). Los resultados muestran que: (a) las narrativas permanecen estáticas, centradas en el presente o en el pasado, con total ausencia de perspectiva de futuro; (b) la familia explica sus dificultades o problemas en base a relaciones directas de causa-efecto (causalidad lineal); (c) la emergencia de singularidades y de reflexividad narrativa es puntual, incapaz de perturbar la narrativa dominante y de ser amplificada por el sistema terapéutico. En base a un modelo de organización de la narrativa en tres niveles lógicos diferenciados, las autoras discuten los resultados obtenidos realzando la necesidad de identificar y trabajar el nivel en que la narrativa está bloqueada para potenciar el cambio terapéutico o de $2^{\circ}$ orden.

Palabras clave: Narrativa, terapia familiar, cambio, fracaso terapéutico.

Sempre que a terapia falha na concretização do seu objetivo fundamental - o de ajudar os clientes a mudar - os terapeutas interrogam-se sobre o que terá corrido mal, procurando aprender com os insucessos. Apesar do interesse e importância dessa reflexão, poucas têm sido as investigações sobre insucessos terapêuticos, nomeadamente no contexto das terapias familiares sistêmicas de enfoque narrativo.

O objetivo deste estudo é compreender quais os aspetos que bloqueiam a mudança narrativa, nomeadamente nas dimensões tempo (estático, flutuante; passado, presente, futuro) e causalidade (linear, circular) das histórias que constituem as narrativas. Estas dimensões revelaram-se preditoras da mudança narrativa em processos de terapia familiar sistêmica (Sequeira \& Alarcão, 2012a).

A intervenção terapêutica pressupõe uma alteração nas narrativas sobre os problemas com que a família chega à terapia (narrativas de $1^{\mathrm{a}}$ ordem) através da construção de narrativas de $2^{\mathrm{a}}$ ordem. Estas narrativas terapêuticas (Carr, 1997) devem desafiar os significados/explicações atribuídos pela família aos problemas/dificuldades e devem possibilitar a construção de novos significados, novas interações e novos comportamentos. O terapeuta desafia a visão que a família tem do problema e da solução, uma vez que esta não conduziu à mudança, mas não pode oferecer uma compreensão do problema e do funcionamento familiar tão radicalmente distinta que a família não se identifique com ela. A acontecer, esta radical diferença de visões potencia uma comunicação simétrica entre terapeutas e família, limita o espaço de construção conjunta de novas histórias e compromete a possibilidade de mudança pela não adesão aos reenquadramentos propostos. A necessidade de incluir outros temas na sessão para que a família deixe de estar fixada na narrativa problema tem sido apontada por vários autores como sendo um aspeto fundamental na mudança terapêutica (e.g., Avid, 2005; Burck, Frosh, Strickland-Clark, \& Morgan, 1998; Frosh, Burck, Strickland-Clark, \& Morgan, 1996; White, 2007; White \& Epston, 1990).

As narrativas são elaboradas para um tempo e para um contexto específicos e têm uma função explicativa e reguladora do próprio sistema. Sempre que se processam alterações no sistema, no seu contexto relacional e social, as narrativas devem integrar esses eventos transformando-se. Nas famílias que procuram a terapia, os problemas assumem, geralmente, um excesso de protagonismo e "anulam ou ocultam" outros aspetos da identidade do sistema familiar ou de cada um dos seus elementos. Nestas circunstâncias, a 
"narrativa problema" (White, 2007), inicialmente desenvolvida para dar sentido e encontrar uma solução para o problema, passa a regular o sistema familiar, a definir papéis, formatos de interação, forma e conteúdo dos discursos, histórias, temas, etc. Se amplificada por audiências relevantes, pode tornar-se uma "macro-narrativa" reguladora e orientadora do sistema, que a mantém, como forma de garantir a sua estabilidade, mas que, simultaneamente, pretende alterá-la face ao sofrimento e mal-estar que comporta. Compete ao terapeuta compreender esta dupla necessidade, ajudando o sistema a mudar embora mantendo a sua identidade e coerência.

Apesar de não existirem estudos específicos que analisem a evolução das narrativas dos clientes em terapias sistêmicas de insucesso, existem alguns trabalhos que sublinham a dificuldade das famílias em abrirem-se a novas visões que contrariem a "narrativa oficial". Vega e Beyebach (2004), ao estudarem a mudança em terapias centradas na solução, concluíram que os clientes que não relatam as melhorias ou avanços por si realizados no início e ao longo das sessões também não as reportam no final, mesmo que estas possam ter ocorrido, o que significa que estas novidades não são valorizadas e amplificadas, nem pela família nem pelo sistema terapêutico. Alguns estudos sobre insucessos em terapias individuais com enfoque narrativo apontam na mesma direção. Gonçalves et al. (2011) descreveram uma retro-alimentação mútua entre MIs e narrativa dominante: quando a emergência de MIs provoca instabilidade nas formas usuais de significar os eventos e origina discrepâncias internas, desencadeia-se uma resposta de anulação do movimento de mudança. Os autores concluem que a retro-alimentação entre a narrativa dominante e os MIs interfere no progresso da terapia, impedindo que os estes adquiram notoriedade na terapia e gerem mudanças na narrativa (ver também Gonçalves, Matos, \& Santos, 2009).

Num outro estudo em que se procedeu à análise da evolução das narrativas em 23 terapias sistêmicas de orientação pós-moderna, observouse a existência de diferenças significativas nas narrativas dos casos de sucesso e de insucesso apenas na última sessão (Sequeira \& Alarcão, 2012a). As terapias estudadas variaram entre 2 e 9 sessões e não foram encontradas diferenças no número de sessões entre os dois grupos, de sucesso e insucesso. O formato e o conteúdo das histórias nas narrativas dos casos de insucesso reassumiu a sua forma inicial no final da terapia, apesar de algumas perturbações ocorridas durante as fases inicial e intermédia. Os resultados desse estudo, em articulação com a compreensão cibernética do funcionamento dos sistemas e com a experiência clínica das autoras como terapeutas familiares, levaram à elaboração de uma leitura cibernética do funcionamento narrativo (Sequeira \& Alarcão, 2012b). Nesta leitura sugere-se que as dimensões que compõem a narrativa estão organizadas em três níveis hierárquicos distintos mas reciprocamente relacionados.

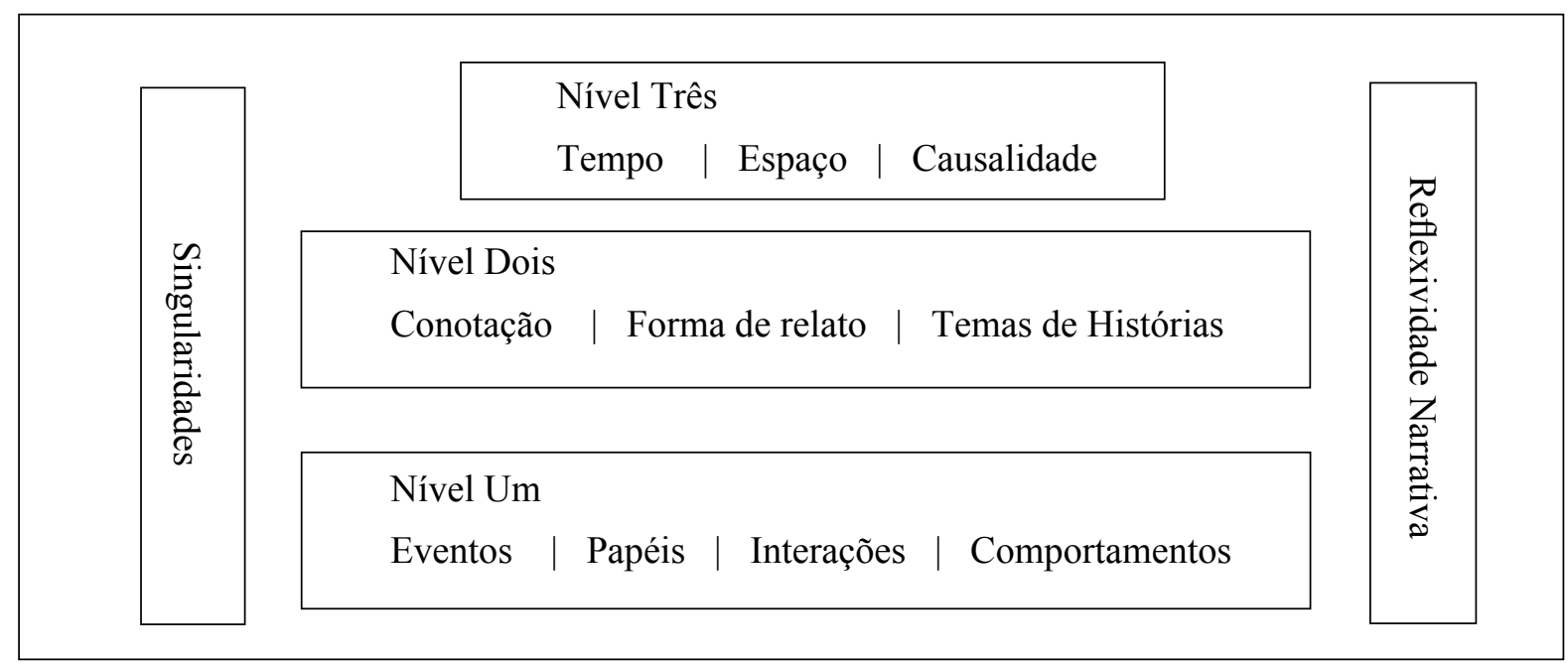

Figura 1. Concepção cibernética da narrativa (níveis, componentes e processos narrativos). 
No nivel um, ou nível inferior da estrutura narrativa, encontram-se as dimensões pragmáticas e comportamentais das histórias, i.e., os discursos específicos sobre os eventos e a participação dos intervenientes (e.g., quem participa, o que faz, o que diz; quais são os comportamentos, interações, relações e como se organizam em seqüências dotadas de significado, denominadas eventos ou acontecimentos). O nivel dois integra a história ou conjuntos de histórias que a família conta acerca de si, do seu quotidiano, das relações e dos eventos, bem como a avaliação moral dos comportamentos dos diferentes protagonistas. No nível três, nível superior da narrativa, encontram-se as dimensões tempo, espaço e causalidade que determinam a forma como os eventos, os personagens e os conteúdos aparecem estruturados em histórias (Elliott, 2005). Este terceiro nível inclui as premissas básicas da construção narrativa que determinam o tempo (passado, pressente e futuro) e o espaço das histórias, bem como a sua estrutura explicativa (causalidade linear e circular). A reflexividade narrativa e as singularidades são processos narrativos que têm como função desbloquear (através da perturbação, questionamento e desconstrução) as dimensões perturbadas das histórias que constituem a(s) narrativa(s) problema(s). A reflexividade narrativa permite desenvolver um olhar "meta" sobre as histórias-problema, sobre o seu processo de construção e os fatores relacionais, discursivos e comportamentais nelas contidos. As singularidades correspondem a novos e eficazes, discursos, comportamentos e cognições, desenvolvidos pelos elementos do sistema familiar face a um problema (Elkaïm, 1990; Sequeira, 2004). Podem ser veiculadas pelos clientes, nos seus relatos espontâneos, ou pelos terapeutas, sempre que surge uma novidade que corresponde a um novo discurso, comportamento ou uma visão alternativa eficaz.

Apesar da importância que as singularidades e a reflexividade narrativa podem ter na perturbação da narrativa problema, o desenvolvimento de narrativas de $2^{\mathrm{a}}$ ordem parece ser dificultado quando não são trabalhadas as dimensões superiores da narrativa, sempre que estas se encontrem bloqueadas.

\section{Método}

O presente estudo integra uma investigação mais vasta sobre mudança narrativa em terapias sistêmicas de orientação pós-moderna que englobou 23 processos de terapia (12 casos de sucesso e 11 de insucesso) num total de 139 sessões analisadas, a partir da aplicação do Sistema de Avaliação da Mudança Narrativa (SAMN; Sequeira \& Alarcão, 2012a). Como adiante se explicita, este sistema permite identificar as mudanças narrativas ocorridas na sessão, a partir de um conjunto de dimensões (Sequeira \& Alarcão, in press).

Metodologicamente, apresenta-se um estudo de caso constituído por 2 processos terapêuticos. O estudo de caso implica um conhecimento profundo da realidade investigada recorrendo a diferentes métodos e técnicas de recolha e de tratamento de informação que se enquadram num paradigma de investigação qualitativa (Yin, 2005).

\section{Participantes}

Famílias. Dois casos de terapia familiar (famílias A e B) que, pertencendo ao grupo dos insucessos $(n=12)$, foram selecionados em função da extensão ( $\mathrm{n}^{\circ}$ de dimensões codificadas) e detalhe da informação ( $n^{\circ}$ de sub-dimensões codificadas) produzida pela aplicação do SAMN, uma vez que se pretende compreender, em profundidade, a forma como (não) se articulou a mudança nas diferentes dimensões narrativas e as razões pelas quais os processos narrativos não contribuíram para a mudança.

As famílias foram seguidas em terapia familiar, entre janeiro de 2005 e janeiro de 2010 , num centro universitário de terapia familiar e de casal. São famílias que voluntariamente procuraram esta consulta de terapia familiar, por iniciativa própria (família A) ou por sugestão do técnico responsável pelo acompanhamento individual do paciente identificado (família B). A terapia da família A envolveu 9 sessões e a da família B 7 sessões (Tabela 1). As duas terapias correspondem a processos concluídos. Os participantes têm uma proveniência socioeconômica médio-alta, correspondendo a famílias que resi- 
dem em meio urbano; os progenitores têm formação superior, estando aposentados, no caso da família A, e a trabalhar, no caso da família B; os filhos da família A estão já graduados e o filho da família B é estudante universitário. As famílias são nucleares intactas e o motivo inicial para a terapia foi o consumo de substâncias (drogas) de um dos elementos.

\section{Tabela 1}

Descrição dos Participantes e Avaliação da Terapia (Famílias A, B)

\begin{tabular}{|c|c|c|c|c|c|c|}
\hline & & & & & \multicolumn{2}{|c|}{ Avaliação da terapia (0-5) } \\
\hline Caso & $\begin{array}{c}\mathrm{N}^{\mathrm{o}} \mathrm{de} \\
\text { sessões }\end{array}$ & $\begin{array}{c}\text { Etapa do } \\
\text { Ciclo Vital }\end{array}$ & Problema & $\begin{array}{l}\text { Tipologia } \\
\text { estrutural }\end{array}$ & Terapeutas & Clientes \\
\hline A & 9 & $\begin{array}{l}\text { Família com } \\
\text { filhos adultos }\end{array}$ & $\begin{array}{l}\text { Consumo de } \\
\text { substâncias }\end{array}$ & $\begin{array}{l}\text { Nuclear } \\
\text { Intacta }\end{array}$ & 2 & 2,25 \\
\hline B & 7 & $\begin{array}{l}\text { Família com } \\
\text { filhos adultos }\end{array}$ & $\begin{array}{l}\text { Consumo de } \\
\text { substâncias }\end{array}$ & $\begin{array}{l}\text { Nuclear } \\
\text { Intacta }\end{array}$ & 2 & 2,5 \\
\hline
\end{tabular}

Terapeutas. As terapias foram desenvolvidas em regime de co-terapia e nelas participaram 4 terapeutas familiares e de casal (com formação em psicologia clínica, docentes universitários, com experiência clínica igual ou superior a 8 anos à data das terapias). As terapias foram desenvolvidas em setting clássico (sala de espelho unidirecional, equipa de observação e gravação vídeo das sessões) e seguiram uma orientação teórica e clínica sistêmica, fortemente inspirada pelos pressupostos das terapias pós-modernas de enfoque narrativo.

Juízes. Três juízes codificaram todas das sessões analisadas. Dois são assistentes sociais com mestrado em psicologia clínica, especialização em família e sistêmica. Foram treinados na codificação de sessões com o Sistema de Avaliação da Mudança Narrativa (SAMN) e participaram em 2 estudos anteriores (Jerónimo, Sequeira, \& Gaspar, 2010; Santos \& Sequeira, 2010) onde codificaram 54 sessões completas de terapia. O terceiro juiz é a primeira autora deste trabalho.

\section{Instrumentos}

Sistema de Avaliação da Mudança Narrati$v a$. O SAMN é um sistema observacional constituído por categorias nominais (Hill, 1992). Permite a análise da mudança narrativa em terapias sistêmicas pós-modernas, através da observação e transcrição das sessões de terapia. O SAMN é constituído por 7 dimensões interligadas, algumas das quais compostas por sub-dimensões (Sequeira \& Alarcão, in press): A- singularidades (A1- discursivas, A2- comportamentais e A3- cognitivas); B- natureza da história, subdividida em 4 eixos (B1- tempo, B2- espaço, B3- causalidade, B4- interações); C- conotação da narrativa; D- forma de relato da história; Ereflexividade narrativa, subdividida em 4 tipos (E1- reflexão sobre a construção narrativa, E2fatores discursivos que mantém a narrativa problema, E3- fatores interacionais que mantém a narrativa problema e E4- fatores comportamentais que mantém a narrativa problema); F- temas da sessão; G- comportamentos alternativos. A definição de cada dimensão e respetivos eixos poderá ser consultada em trabalhos anteriores de apresentação e descrição do SAMN (Sequeira \& Alarcão, in press).

O SAMN possui boa fidelidade (medida de acordo interjuízes) com Kappas que variam entre excelente e suficiente [A (singularidades) $\left(k_{\mathrm{A} 1}\right.$ sing.disc $=0,68, k_{\mathrm{A} 2 \text { sing.comp }}=0,78, k_{\mathrm{A} 3 \text { sing. cogn }}=0,79$; $\mathrm{B}$ (natureza da história) $k_{\mathrm{B} 1 \text { tempo }}=0,83, k_{\mathrm{B} 2 \text { espaço }}=$ $1,00, k_{\mathrm{B} 3 \text { causalidade }}=0,76$; $\mathrm{C}$ (conotação da narrativa) $k_{C}=0,64 ; \mathrm{D}$ (forma de relato da história) $k_{\mathrm{D}}$ $=0,75 ; \mathrm{E}$ (reflexividade narrativa), $k_{\mathrm{E} 1}=0,79, k_{\mathrm{E} 2}$ $=0,60, k_{\mathrm{E} 3}=0,52, k_{\mathrm{E} 4}=0,63 ; \mathrm{F}$ (temas da sessão) $k_{\mathrm{F}}=0,95, \mathrm{G}$ (comportamentos alternativos) $k_{\mathrm{G}}=$ 0,66] (Sequeira \& Alarcão, 2012c).

Questionário de Avaliação do Processo Terapêutico. Terapeutas e famílias avaliaram, 
numa escala Likert de 1 a 5 ( $1=$ muito pouco e 5 = muito), as terapias considerando: (a) o resultado geral da mesma, (b) a concretização dos objetivos da terapia, (c) a melhoria dos problemas e (d) a melhoria geral das relações na família no final da terapia. As famílias foram contatadas por telefone para responderem ao referido questionário. Foi ainda avaliado o cumprimento dos objetivos, definidos entre clientes e terapeutas na altura do estabelecimento do contrato terapêutico, no sentido de informar sobre a concretização das metas definidas. Esta informação foi integrada na avaliação do sucesso/insucesso da terapia. Assim, os insucessos correspondem a uma média das classificações inferior a 2,5 pontos no questionário de avaliação do processo terapêutico e à não concretização da maioria dos objetivos definidos para a terapia (Tabela 1)

\section{Procedimentos}

Terapia. As terapias foram desenvolvidas de acordo com a abordagem sistêmica pós-moderna de enfoque narrativo e centraram-se na transformação das histórias e narrativas das famílias. A terapia sistêmica é uma forma de psicoterapia que equaciona os comportamentos, em particular os sintomas de sofrimento mental, no contexto das relações e sistemas sociais nos quais os indivíduos vivem. Foca-se e intervém nas relações interpessoais, nos processos discursivos de construção social das realidades e na causalidade recursiva entre os sintomas e interações. Os elementos da família e outras pessoas importantes, como amigos, técnicos, vizinhos, podem ser incluídos na terapia, direta ou virtualmente, através de questões orientadas sistemicamente para os seus comportamentos, cognições e discursos (Sydow, Beher, Schweitze, \& Retzlaff, 2010).

As terapias de enfoque narrativo direcionam-se para a transformação das histórias associadas aos problemas e para a construção de novas histórias que sejam mais capazes de responder às formas preferidas das pessoas serem e de se verem (Freedman \& Combs, 2008). Assim a terapia narrativa envolve a identificação e compreensão dos discursos (pessoais, familiares e culturais) associados ao problema, os processos de desconstrução e questionamento das nar- rativas que limitam ou constrangem a família e a re-autoria ou elaboração de novas histórias para significar as dificuldades e as pessoas nelas envolvidas (White, 2007; White \& Eptson, 1990).

Recolha e Tratamento dos Dados. Foi consentida a utilização dos dados das sessões, mediante garantia de confidencialidade. Assim, apenas os conteúdos e discursos relevantes para a análise, apresentados de forma a não serem identificados os participantes, são incluídos neste trabalho. As sessões de terapia foram analisadas, seqüencialmente, através do SAMN (da $1^{\mathrm{a}}, 2^{\mathrm{a}}, 3^{\mathrm{a}} \ldots$ até à última, depois de concluídos os processos terapêuticos). O processo de codificação requer a observação e transcrição integral das sessões de terapia. Primeiro são identificados os episódios narrativos da sessão (trechos da sessão que se organizam em torno de um tema) e depois são efetuadas avaliações sobre as dimensões presentes nos discursos. Cada dimensão é inicialmente codificada como estando presente/ ausente e, posteriormente, é feita a contabilização das ocorrências (e.g. tipo e número de singularidades) ou detalhada a classificação nominal (e.g. tempo estático, tempo flutuante; passado, presente, futuro). Todas as sessões foram codificadas por dois juízes: cada juiz codificou as sessões individualmente e, posteriormente, foram discutidas as dúvidas e desacordos até definição da codificação final.

\section{Resultados}

Cada família será brevemente descrita. São enunciados os aspetos narrativos mais relevantes, a partir da codificação feita com o SAMN, e apresentados trechos do discurso dos participantes elucidativos das dimensões em análise.

\section{Família $A$}

A família é constituída por 4 elementos: os pais, ambos aposentados e com idades perto dos 60 anos, e dois filhos jovens adultos, graduados, a residir em casa dos pais. O PI (paciente identificado), 34 anos, tem um trabalho incerto (em regime de colaboração pontual, sem contrato de trabalho) na sua área de formação. A irmã, 29 anos, encontra-se a fazer uma formação pós-gra- 
duada e apenas estuda. O PI tem um filho pequeno, fruto de uma relação ocasional, que está quinzenalmente com o pai aos fins de semana.

Foi a irmã quem solicitou a terapia e o motivo foram os consumos de drogas (haxixe) do PI e a incapacidade da família para o ajudar a ultrapassar este problema. $\mathrm{Na} 2^{\mathrm{a}}$ sessão foi proposto um contrato de 6 sessões, seguidas de 3 follow-ups para ajudar a família a criar espaço para: (a) cada um falar de coisas importantes sobre as quais não conseguem conversar e (b) para lidarem melhor com o consumo de drogas. Foram realizadas 9 sessões ( 2 de avaliação, 5 de contrato e 2 follow-ups). Embora o contrato fosse de 6 sessões foram realizadas apenas 5 sessões por acordo entre terapeutas e família. O PI apenas esteve presente até à $4^{\mathrm{a}}$ sessão. As sessões centraram-se nos problemas do PI.

\section{Avaliação das Dimensões da Narrativa a partir do SAMN.}

Singularidades. Com exceção das sessões 3 e 4, ocorreram singularidades discursivas, comportamentais e cognitivas ao longo das sessões (com particular incidência na $5^{\mathrm{a}}$ sessão), embora não tenham sido amplificadas, nem pela família, que raramente lhes conferiu importância, nem pelo contexto terapêutico que não as pontuou de forma sistemática nem criou espaço, na conversa terapêutica, para que fossem valorizadas. As singularidades que emergiram nas sessões estão relacionadas com atitudes e discursos das pessoas da família face ao PI, relativizando os seus consumos e comportamentos. Nenhuma das singularidades identificadas foi protagonizada pelo PI.

\section{Sessão 2}

Pai: "Tenho que dizer que na semana passada o meu filho não mentiu. Foi capaz de dizer que tinha sido ele que tinha mexido no dinheiro. Já sabíamos, mas foi importante ele assumir" (A1).

Mãe: "Falamos finalmente com a nossa familia mais afastada sobre o problema do meu filho. Nunca o tínhamos feito antes" (A1 e A2).

Irmã: "Cada um de nós tem de perceber como podemos melhorar como pessoas e como família... Centramo-nos muito nele, mas sabe-se lá se não há mais coisas que nos bloqueiam. Deve haver!" (A3).

\section{Sessão 9}

Terapeuta: "Quais as coisas boas que identifica no seu filho?"

Pai: "A única coisa boa nele é a relação que tem com o filho. E é só por isso que não o colocamos fora de casa" (A1).

Tempo. As narrativas apresentaram um tempo estático, com predominância do presente. Apenas na $5^{\text {a }}$ sessão, quando da discussão da tarefa prescrita para casa ("o que têm de fazer para ganhar algumas batalhas sobre o problema"), surgiram algumas referências ao futuro (protagonizadas pela mãe). Foram identificadas várias tentativas de perturbação da dimensão tempo (e.g., identificação de exceções; possíveis soluções), às quais a família respondeu centrando-se no presente, o que revela a sua dificuldade de equacionar o futuro.

\section{Sessão 2}

Terapeuta: "Quais são os passos a seguir?" PI: "Não sei. Não consigo pensar no futuro... Não sei se terei de viver sozinho. Também vou ficar sem trabalho, logo o futuro não é bom".

Pai: "Não vejo nada para o futuro. Nada parece ser diferente do que foi e do que é. Sou pessimista porque não tenho esperança no futuro. Um dia quando eu faltar não sei como será!"”

\section{Sessão 4}

Terapeuta: "Como era há 5 anos atrás?" Mãe: "Igual, ele nunca deu um passo, fomos sempre nós a empurrá-lo".

\section{Sessão 5}

Mãe: "Quanto ao que posso fazer para vencer a 'agitação', posso passar a dar mais espaço, ser mais exigente, mais firme, mais clara, impor regras, ser mais compreensiva ... relativizar mais os problemas".

Pai: "Quanto ao que posso fazer para vencer à 'agitação', pensar mais e ser mais exigente, nada mais me ocorre, porque já tudo 
foi feito e nada resultou. A única solução seria um novo internamento".

\section{Sessão 7}

Terapeuta: "Quais são os vossos planos de casal para o futuro, não enquanto pais, mas como casal?"

Pai: "Não temos objetivos, vivemos um clima de desconforto, angústia e ansiedade. Para $j a ́$, pensamos apenas no que estamos a viver". Mãe: "No dia em que ele sair não sei como será, mas imagino que a angústia e ansiedade vão aumentar... Vejo um clima muito negro!"

Espaço. As narrativas familiares não são espacialmente contextualizadas, nomeadamente quando é feita referência aos comportamentos sintomáticos do PI.

\section{Sessão 2}

Terapeuta: "Quando é que o problema se manifesta mais?"

Mãe: "Não sei dizer. A mim parece-me que é sempre".

PI: "É dificil responder... Não há relação com nada... Não é em casa, não é no trabalho..."

\section{Sessão 4}

Pai: "Seja qual for a situação este problema está sempre lá!"

Causalidade. Os discursos da família evidenciaram uma construção linear, centrada exclusivamente nas causas ou, muito esporadicamente, nos efeitos do consumo e nos problemas que dele resultaram. As dificuldades relacionais do PI e os seus comportamentos desajustados são explicados pelo consumo de substâncias. Também as dificuldades da família (e.g., angústia, tristeza, preocupação dos pais, impossibilidade de fazerem outras coisas) são explicadas como resultado de haver um filho toxicômano de quem é preciso "tratar". Em determinada altura, a família assume que se o filho não consumisse não haveria problemas. O PI protagoniza uma perspectiva linear, complementar à da família: consumia porque se sentia melhor, mais motivado, com projetos e mais capaz de estar com os outros. Não identifica outros problemas na família que não o seu consumo e os que dele derivam, reproduzindo totalmente a narrativa oficial. As tentativas dos terapeutas de inclusão da circularidade foram pouco freqüentes mas, quando aconteceram, a família respondeu-lhes com uma leitura linear e causal dos fatos.

Sessão 2

PI: "Quando consumo a minha autoestima aumenta o que leva a que pense em objetivos, por exemplo, melhorar neste ou naquele aspeto, poupar dinheiro para comprar um carro, etc. É isso que me leva a consumir". Mãe: "Nós somos uma família prisioneira do problema do meu filho, não conseguimos viver para além dele. Quero a liberdade dele e a nossa, se ele se tratar nós ficamos bem!"

\section{Sessão 5:}

Terapeuta: "O que podem vocês fazer para ganhar a batalha?"

Irmã: "Podemos também não estar sempre focados nele, dar-lhe mais confiança isso ajuda, pois também permite não ver só o que ele faz mal..."

Pai: "Ele não faz o que devia ser feito, logo eu também não sei como fazer de outra maneira".

Sessão 9:

Terapeuta: "Quando foi a última vez que elogiou o seu filho? Qual seria a reação dele?" Pai: "As maiores asneiras dele foram sempre depois de um elogio..."

Interações. As interações centram-se no sintoma. Os papéis estão claramente definidos em função do sintoma - o "doente" (PI) e os "cuidadores" (restante família). Apenas nas sessões $4 \mathrm{e}$ 5 as interações incluem discussão de conflitos e não de sintomas.

Sessão 1

Mãe: "Tenho um filho toxicômano que só pensa na droga e nós temos de ajudá-lo a sair deste pesadelo!"

Pai: "Ele nunca tentou nada, sentiu-se pressionado e sujeitou-se a ir. Temos de o controlar em tudo, eu, a mãe e a irmã". 
PI: "É verdade! Sei que se fizer tudo mal, se gastar o meu dinheiro todo eles acabam por me dar mais".

\section{Sessão 4}

Pai: "Eu e ele tivemos uma discussão, temos pontos de vista diferentes. Só assim soube claramente o que ele pensa sem que a droga estivesse lá".

Conotação da narrativa. Não ocorrem oscilações quanto à conotação das histórias; o PI é descrito como doente e mal intencionado, os seus comportamentos anormais e ilegítimos; a restante família é conotada como "bem intencionada".

Sessão 1

Mãe: "Ele está doente! Muito doente, o que ele faz não é normal!"

\section{Sessão 2}

Pai: "Ele nem sequer se preocupa com a família, se nos magoa, não interessa o que importa é ele. É inaceitável!"

\section{Sessão 7}

Irmã: "Ele sempre foi tímido e sempre teve problemas de inserção e acho que isso o afetou e justifica as dificuldades presentes".

Forma de relato da história. A perceção de incompetência pontua os relatos da família que, com frequência, sublinha o seu fracasso nas ajudas ao PI. Esta visão de incapacidade familiar sofreu ligeiras alterações em sessões em que o PI alterou o comportamento no sentido desejado pelos pais (sessão 1 e 2). Apesar destas oscilações, não se observou nenhuma amplificação ou valorização das mesmas para outros contextos ou momentos posteriores. A visão do PI, sobre si e sobre a família, mostrou-se complementar à dos restantes elementos. Apenas pontualmente, e em referência à sua vida pessoal, a mãe e a irmã manifestaram uma perspectiva ativa e competente.

\section{Sessão 1}

Pai: "Ele não tem vontade própria, não é capaz por si de fazer nada e nós também não temos conseguido ajudá-lo".

\begin{abstract}
Sessão 2
PI: "Estou a fazer um trabalho que foi dificil de conseguir mas que está a correr muito bem. Eu estou feliz por ter conseguido e sei que os meus pais também estão!'
\end{abstract}

Sessão 6

Mãe: "Não consigo falar com ele. Sinto uma frustração enorme de não saber como lá chegar. Não consigo!”

Sessão 7

Pai: "Não conseguimos colocá-lo na rua. Talvez fosse importante ele passar por isso, mas não somos capazes. Ele está cada vez pior, não faz nada, não procura fazer por si e nós limitamo-nos a assistir à decadência".

\section{Sessão 9}

Pai: "Os progressos da parte do nosso filho são zero! Não podemos fazer nada, ele não quer!"

Irmã: "Ele não tem força para lidar com a tristeza e ela vai acabar com ele..."

Reflexividade narrativa. A identificação e reconhecimento dos aspetos que promovem ou mantêm o problema iniciou-se na $2^{\mathrm{a}}$ sessão, ocorrendo em quase todas as outras, com exceção da $3^{\mathrm{a}}$ e $8^{\mathrm{a}}$. No entanto, a generalidade das reflexões desenvolvidas na sessão não foram amplificadas para outros contextos nem perduraram para além da sessão.

Sessão 2

PI: "Há coisas que ainda acontecem e que têm de mudar. A forma como me relaciono com a família: estou sempre sujeito a críticas, eles estão sempre preocupados comigo e eu com eles, com o que pensam, como vão reagir ao que faço, bem, mal... Estamos muito dependentes uns dos outros e isso não só não ajuda como aumenta as dificuldades".

Pai: "Dificilmente em casa podemos ter conversas pois há sempre interrupções, críticas, coisas que não podem ser faladas, verdades que nunca se resolvem..." 
Sessão 6

Irmã: "O meu irmão não se quer preocupar com o futuro, não quer aceitar o que a vida é e nós não o obrigamos a ver, colaboramos na cegueira dele. Ele não precisa de mudar, tem tudo!"

\section{Sessão 9}

Mãe: "Continuo a pensar muito neste problema, estou sempre a ruminar e isso eu já sei que é muito mau, não consigo evitar. A minha filha lida melhor com a situação porque está ocupada, não tem tanto tempo para pensar nisto... A mim as coisas não me saem da cabeça!"

Temas da sessão. Os discursos focam-se no sintoma e no comportamento do PI e nos seus efeitos na vida familiar. Nas sessões 2, 5 e 7 falou-se, adicionalmente, de acontecimentos positivos e das competências que a família tem para "vencer a batalha do problema". A emergência de temas "não problema" deveu-se, contudo, à prescrição de tarefas que exigiam a focalização em dimensões alternativas ao sintoma e às quais a família aderiu.

Comportamentos alternativos. Nas sessões 6 e 7 a família relatou ter procedido de forma diferente face ao PI, embora sem sucesso. Numa situação em que o PI faltou a um compromisso importante, os pais, ao invés de o repreenderem, atuaram como se nada fosse, mas a reação do filho não se alterou, agindo com indiferença. Numa outra situação, o pai tirou-lhe as chaves de casa e deixou-o na rua, por ter chegado depois da hora combinada. No entanto, o filho voltou a chegar atrasado noutras ocasiões.

\section{Família B}

O pai e a mãe, ambos com cerca de 60 anos, e o filho, com 22 anos, coabitam apenas ao fim de semana porque o filho estuda noutra cidade. Os pais são técnicos superiores e trabalham. É o filho que faz o pedido de terapia apontando como motivo o consumo de substâncias, a má a relação com os pais e o insucesso escolar. Está a tentar adaptar-se a um segundo curso superior mas as coisas estão a correr mal. À data do início da terapia encontrava-se abstinente de drogas e era seguido por um psicólogo e um psiquiatra. Para os pais os motivos da terapia são o consumo de substâncias, o insucesso escolar do filho e os conflitos familiares. Foram aconselhados, pelo psicólogo e psiquiatra, a serem seguidos em terapia familiar. $\mathrm{Na} 2^{\mathrm{a}}$ sessão foi definido um contrato de mais 5 sessões com o objetivo de: (a) "ajustar" as relações familiares, (b) melhorar a forma como comunicam e (c) desenvolver estratégias para equacionarem o futuro de forma mais refletida, encontrando conjuntamente soluções para os desafios, em particular para o problema do PI. Foram realizadas 7 sessões. O PI não compareceu nas sessões 6 e 7 .

\section{Avaliação das Dimensões da Narrativa a partir do SAMN.}

Singularidades. Embora esta dimensão tenha sido freqüentemente promovida pelos terapeutas, ao longo de toda a terapia, as singularidade surgiram em número reduzido e não foram verdadeiramente integradas pela família. As mais freqüentes foram as comportamentais (e.g., esforços do PI em alterar o seu dia a dia, mudança da interação mãe-filho).

\section{Sessão 1}

Terapeuta: "Quando e como falaram de forma satisfatória sobre os vossos problemas?" Pai: "Não conseguimos falar sobre nada. Isso nunca aconteceu".

PI: "Estou satisfeito por ter conseguido ir ao ginásio, inscrever-me e freqüentar..." (A2) Terapeuta: "Como poderias mobilizar essa energia para fazeres também outras coisas?" PI: "Acho que não consigo. Consegui desta vez mas mais não sei..."

Sessão 3

Terapeuta: "Mantiveste as conquistas da última sessão?"

PI: "Não, Estou novamente mais sozinho, não tenho falado com ninguém... a época de exames é difícil. Não tenho ido ao ginásio..." Terapeuta: "Tem orgulho da inteligência do seu filho? Em que dimensões o considera inteligente?" 
Pai: "Infelizmente ele faz um péssimo uso da inteligência dele".

Sessão 4

Mãe: "Depois da nossa conversa passei a ligar-lhe só uma vez por dia. Foi dificil mas consegui!" (A2)

Tempo. Até à $4^{\mathrm{a}}$ sessão, o tempo é estático e focalizado no presente. A partir da $5^{\text {a }}$ sessão oscilou entre referências ao passado e ao presente. Apesar dos terapeutas promoverem, com insistência, a flexibilidade temporal, o futuro foi dificilmente equacionado e a sua a concretização definida de forma muito vaga (vide respostas à pergunta milagre).

\section{Sessão 1}

Mãe: "Na verdade não há nada diferente. Temos os problemas que sempre tivemos. Problemas e mais problemas. Antes era o pai, agora é o filho".

\section{Sessão 4}

Terapeuta: "Quais são os teus planos se o estudo não correr bem?"

PI: "Não sei, não tenho confiança nenhuma em mim. Não vejo um futuro nada bom..."

\section{Sessão 6}

Terapeuta: "Imaginem que acontecia um milagre e que o problema estava resolvido; mas que ele tinha acontecido enquanto dormiam $e$, por isso, não sabiam que tinha acontecido. Como dariam conta? O que estaria diferente na vossa vida e no vosso filho?"

Mãe: "Ele estaria livre... ia à faculdade ou ia trabalhar, cumpria horários e tinha amigos da idade dele".

Pai: "Ele teria uma vida. Agora não tem. Estaria vivo, pois agora não está, está morto!"

Espaço. Excetuando as narrativas sobre acontecimentos específicos relacionados com os problemas do filho, que foram espacial e temporalmente contextualizadas, todas as outras narrativas foram acontextuais nas fases inicial e intermédia da terapia, tornando-se contextuais apenas nas 2 últimas sessões.

\begin{abstract}
Sessão 1
Terapeuta: "Imagine que numa situação em que o fosse visitar estava tudo como a mãe queria. Como o encontraria, onde estava e a fazer o quê?"

Mãe: "Estava bem disposto, alegre, a contar coisas. Onde estava? Não sei, estava a fazer qualquer coisa, não sei..."
\end{abstract}

\section{Sessão 2 \\ Pai: "Passou-se uma coisa muito grave. $O$ meu filho agrediu-me violentamente, sem razão nenhuma. Estávamos em casa e já eram seis da manhã e ele ainda estava ao computador, ia ter exame e não tinha estu- dado nada. Eu fui ao quarto dele ..."}

Causalidade. A causalidade narrativa foi sempre linear. Para os pais a causa dos comportamentos ou atributos negativos do PI, como a preguiça ou a passividade, derivavam da toxicomania e das "psicoses". Embora na $1^{\text {a }}$ sessão tenha sido introduzido pelo pai o seu antigo problema de dependência, a família não refletiu sobre "como é que as soluções do pai podiam ajudar a família", apesar dos terapeutas procurarem explicitamente fazer esta ligação.

\section{Sessão 1}

Pai: "Ele é de facto doente! Para mudar de vida ele tem de começar por deixar as drogas! ... O meu filho aprendeu a mentir na infância ao ver-me esconder bebida, houve situações de violência e ele e a mãe tiveram de sair de casa. Entretanto as coisas não eram faladas, eram camufladas e este processo de fuga à realidade arrastou-se até aos 11 anos. Ele teve problemas graves na escola, gozavam com ele por causa disto! Vivemos cada um para seu lado, não partilhamos nada". Terapeuta: "Como é que essa experiência vos pode ajudar atualmente?"

Pai: "Se eu fui capaz ele também tem de ser, só depende dele. Nada está nas nossas mãos!"

Sessão 4

PI: "O haxixe ajuda-me. Há 3 dias que não consumo e isso faz com que tenha mais difi- 
culdade em sair da cama, em ir à rua, estar com pessoas... Fico mais deprimido".

Sessão 5

Pai: "A psiquiatra diz que ele tem psicoses graves! Ele não diz uma verdade desde os 10 anos. Está doente e os problemas derivam dai".

\section{Sessão 7}

Mãe: "Acredito que se ele se tratar depois de vir da comunidade terapêutica fica tudo bem. As outras dificuldades não têm importância face a este problema".

Interações. As interações estabelecem-se em função do PI e dos seus comportamentos e intenções. Os papéis e as regras estão definidos em função da narrativa problema: filho problemático, mãe preocupada e protetora, pai exigente e emocionalmente distante. Apesar das tentativas recorrentes dos terapeutas, de flexibilização dos papéis, mãe e pai mantiveram rigidamente os seus papéis.

\section{Sessão 1}

Mãe: "O meu filho é uma pessoa que desespera facilmente basta que as coisas não sejam como ele pensou! Depois lá vou eu tentar motivá-lo, ajudá-lo a fazer o que é preciso, enfim... ver se ele se anima e faz as coisas. O meu marido irrita-se muito com as atitudes dele, é uma pessoa menos tolerante e, por isso, sou eu que tento mais vezes falar com o nosso filho".

\section{Sessão 3}

Pai: "Eu limito-me a dar dinheiro e tratar da ida às consultas. Fora isto não há conversas... Nem coisas banais, futebol, etc. Nestes anos todos o meu filho nunca me telefonou!"

Terapeuta: "Como poderiam dividir melhor as responsabilidades e tarefas de forma a que o pai estivesse mais presente e a mãe menos sobrecarregada?"

Mãe: "Não sei, eu faço porque tem de ser. Se não for eu não acontece nada..."

Pai: "Eu perco a paciência. Não consigo aceitar a postura dele".

\author{
Sessão 7 \\ Terapeuta: "Como gerem agora a vossa \\ vida?"
}

Mãe: “Agora estamos só os dois. Temos menos dificuldades, pois os problemas maiores não estão lá. Mas ainda há conflitos que resultam de coisas simples mas que se tornam grande problemas!"

Conotação da narrativa. O PI foi conotado como doente e anormal, por vezes mal intencionado. O PI esforçou-se por contrariar a narrativa de má-intenção, argumentando que não faz um conjunto de coisas com o objetivo de magoar mas sim porque "perde a cabeça." Os pais conotam como bem intencionadas as suas atitudes face ao filho, mesmo que ele não concorde.

Sessão 1

Mãe: "Vejo o meu filho como uma pessoa doente, está perdido, triste, não é capaz de aceitar a ajuda que precisa".

\section{Sessão 2}

Pai: "Ele agrediu-me propositadamente! É mau. Eu apenas queria ajudá-lo, por isso fui ao quarto tentar desligar o computador".

PI: "Sinto-me diferente das outras pessoas... ando num psicólogo, numa psiquiatra e nestas consultas... pareço um atrasadinho!"

Sessão 4

Mãe: "Eu gosto muito de ti meu filho mas tu não queres colaborar. Isto não está bem! Ontem faltaste à psiquiatra, hoje chegas a esta hora... queres que eu te abandone? Só vejo essa solução! Eu não mereço que me faças isto!"

Forma de relato da história. A incompetência e incapacidade do PI dominaram os relatos das sessões. Os pais vêem-se como ativos na forma de lidar com o problema do filho.

Sessão 1

Terapeuta: "Como é que os pais te olham nesta altura?" [pergunta colocada depois da identificação de uma A2]. 
PI: "Da mesma forma de sempre, à toa, desorientado, perdido, que é também como eu me vejo!"

Sessão 4

Pai: "Ele está cada vez pior, só um internamento, mas ele tem de ter força de vontade e não tem. Nós tentamos motivá-lo mas tem de ser ele".

\section{Sessão 5}

Mãe: "Vamos esperar para ver o que isto dá. Estamos também a pensar levá-lo para a casa de campo para ver se conseguimos... Eu vou tentar ajudá-lo a estudar para os exames".

Reflexividade narrativa. A reflexão sobre os aspetos que promovem ou mantêm o problema aconteceu a partir da $2^{\mathrm{a}}$ sessão, embora de forma irregular e pouco consistente. Os pais estavam fixados na idéia do internamento e esta visão (reforçada pelos outros profissionais) não foi questionada na terapia familiar, nem promovida reflexão sobre a sua utilidade para a resolução do problema e postura do filho. Apenas na última sessão os pais abordam a importância de mudarem algumas coisas entre si para serem mais funcionais quando o filho voltasse da comunidade terapêutica.

\section{Sessão 7}

Mãe: "Devíamos mudar algumas coisas para que quando ele voltasse estivéssemos mais fortes. Isso também o ajudaria. As técnicas da comunidade têm dito isso e eu concordo".

Terapeuta: "E o que deveriam mudar?" Mãe: "Temos dificuldade em falar de coisas importantes, mantém-se este problema que nos pode fragilizar".

Pai: "Devíamos ter uma relação mais funcional, mais solidária e mais próxima”.

Temas da sessão. As narrativas-problema foram completamente dominantes, quer em relação aos problemas atuais do filho quer em relação aos problemas passados dos pais.

\section{Discussão}

A análise efetuada permitiu perceber que há duas dimensões centrais - o tempo (estático) e a causalidade (linear) - que não sofrem alterações ao longo das sessões, supondo-se que isso possa ter tido implicações importantes na concretização da acoplagem terapêutica, ou seja na construção de uma narrativa conjunta partilhada pela família e pelos terapeutas. As singularidades e a reflexividade narrativa, embora tenham ocorrido pontualmente, não geraram perturbação suficiente para desbloquear a temporalidade estática das histórias (centradas no passado ou no presente) ou a causalidade linear com que as famílias explicavam os problemas. A introdução de oscilação temporal, com recurso a narrativas que retratassem, detalhadamente, os vários momentos da vida familiar não foi de todo possível na família A e aconteceu pontualmente na família B. Mais complexa, contudo, foi a introdução do tempo futuro: pensar sobre o que poderia vir a ser a família, as pessoas, os acontecimentos ou pensar sobre as mudanças desejadas, foi uma tarefa não equacionável no espaço e no tempo da terapia embora este esforço tenha sido feito pelos terapeutas (e.g., colocação da questão milagre, na família B).

A permanência de uma temporalidade estática, ou apenas flutuante entre o tempo passado e presente, encontra-se ligada à manutenção da temática sintoma, mesmo quando o comportamento sintomático que trouxe a família à terapia já desapareceu, como era o caso da família B. O domínio destas narrativas, do passado e/ou do presente, parece manter um ciclo de retro-alimentação das dificuldades, como aconteceu nas famílias analisadas nas quais o passado estava conotado por eventos traumáticos, alguns deles entendidos como causas do sintoma e das dificuldades atuais (causalidade linear). Nestas situações, parece importante que a história familiar e os problemas passados possam ser equacionados como recursos para o futuro, capitalizando capacidades que a família tem mas que, porque dominadas por uma atribuição causal problemática, não conseguem ser positivamente pontuadas nem mobilizadas a favor da mudança. No caso 
da família B, por exemplo, poderia ter sido interessante debater com a família quais foram os fatores que mais ajudaram o pai a resolver a sua dependência do álcool, o que o ajudou a tomar a decisão de parar de beber, o que pode ser semelhante ou diferente com o seu filho, assim como as situações ou os comportamentos das pessoas (dele próprio e dos outros elementos da família) que mais contribuíram, no passado, para a manutenção do problema, ou para a sua solução, refletindo sobre a forma como essa experiência pode ser, no presente e no futuro, um apoio ou uma armadilha para as mudanças que a família quer implementar.

A causalidade das narrativas foi sempre linear. Nas famílias estudadas, o facto de os diversos elementos terem explicações coincidentes ou complementares sobre os problemas e sobre os eventos não permitiu que os exercícios de reflexividade narrativa e as singularidades emergentes fossem aceites e amplificados por parte da família e dos próprios terapeutas. A existência de explicações opostas, sobre o problema, quando assumidas como mutuamente exclusivas, rigidificam as narrativas e alimentam a causalidade linear, dificultando a acoplagem terapêutica em processos terapêuticos que repousam numa epistemologia circular e na construção de narrativas de $2^{\mathrm{a}}$ ordem (Carr, 1997), como é o caso das terapias sistêmicas.

O pressuposto central do pensamento e da intervenção sistêmica, que a diferencia de outras abordagens terapêuticas, é a complexidade. Apoiando-se em técnicas como o interrogatório circular, a conotação positiva ou o reenquadramento, o terapeuta sistêmico promove a emergência e a amplificação de singularidades e potencia a reflexividade narrativa. A finalidade é criar condições para a emergência de novas narrativas (perspectivas, discursos, comportamentos), mais complexas e capazes de integrar, explicar e transformar os problemas a partir do desenvolvimento de um novo modelo de compreensão dos eventos. Nos casos estudados não foi identificada uma narrativa conjunta, por parte do sistema terapêtico, sobre o problema, sobre a família e até sobre a terapia. Pelo contrário, distinguiram-se pelo menos duas narrativas: a da família, que se manteve próxima da original, e a dos terapeutas, que não gerou pontos de contacto com a da família. A ausência do PI, na família A, a partir da sessão 4 poderá ter também contribuído para esta impossibilidade de negociação e modificação das perspectivas existentes sobre o problema e de co-construção de uma versão conjunta, já que a família interpretou esta ausência como mais uma evidência de que o problema era o PI e os seus comportamentos desadequados.

A construção de uma narrativa conjunta poderia ter sido alternativamente trabalhada através do questionamento, continuado, das explicações da família para os eventos que fazem parte da sua vida. Teria sido muito interessante, nas duas famílias, exercitar explicitamente outras possibilidades explicativas das histórias da família e dos seus elementos, percorrendo o eixo do tempo, por exemplo, através do genograma, fotograma, de esculturas da família em diferentes momentos. Desta forma poderia gerar-se uma perturbação temporal nas histórias relatadas e promover reflexões sobre o que o passado ensina para o presente e para o futuro. Tal exploração poderia abrir espaço para a construção de outras explicações para os acontecimentos, mais assentes na circularidade e complexidade.

Nos casos estudados deve sublinhar-se a importância das narrativas psicopatológicas, que tiveram o poder de organizar a identidade e os papéis dos sujeitos e ofereceram uma solução simples para o problema - "tratar a pessoa doente". Naturalmente, a adesão a esta perspectiva é muito tentadora e aparentemente mais segura para as famílias (que procuram a mudança do sintoma sem a alteração das regras de funcionamento familiar), embora seja totalmente oposta à perspectiva sistêmica e pós-moderna (Avid, 2005; Gergen, Hoffman, \& Anderson, 1995). A discussão destas narrativas na terapia parece ser de extrema importância. O questionamento da utilidade e das limitações que as narrativas psicopatológicas colocam à família, no que se refere à compreensão: (a) da etiologia das dificuldades e dos sintomas, (b) dos papéis, (c) das relações, da identidade de cada pessoa e da família, (d) das possibilidades de mudança, (e) das conseqüências da manutenção dessas narrativas, 
(f) da discussão sobre o papel de outros elementos significativos, como por exemplo profissionais de saúde, amigos, etc., na origem e manutenção destas narrativas, permitirá desenvolver um olhar mais alargado sobre as dificuldades bem como sobre os aspetos que as mantêm e que bloqueiam a mudança, na família e nas relação entre esta e outros sistemas sociais importantes.

A impossibilidade de aceder a uma visão circular dos eventos e dos comportamentos parece bloquear a construção de uma narrativa terapêutica nova, capaz de gerar mudança nas narrativas-problema e de libertar a família, abrindo-a a novas pontuações e a novas interações. Nos casos estudados, as singularidades surgem ao longo da terapia mas não são amplificadas pela família, apesar de algumas tentativas feitas pelos terapeutas. Os elementos de ambas as famílias desvalorizam ou anulam a novidade trazida por essas singularidades, contrapondo-lhe relatos, comportamentos e interações da narrativa dominante, como se não se permitissem equacionar outra que não a visão "oficial" do problema. É nesse sentido que se considera que quando estão bloqueados os níveis superiores da narrativa (nível dois, dos temas das histórias e da sua conotação moral, ou nível três, do tempo, causalidade ou espaço da narrativa), a emergência de singularidades ou de momentos de reflexão sobre a narrativa problema é rapidamente anulada não deixando que se alimentem novas visões e novas experiências relacionais que poderiam conduzir a família a mudanças qualitativas ou de $2^{\mathrm{a}}$ ordem. Por exemplo, na família A é muito clara a dificuldade que qualquer um dos elementos tem em projetar-se no futuro (o PI chega mesmo a afirmar que não consegue pensar no futuro), enredados que estão no problema dos consumos e do comportamento do PI. Desta forma, não há espaço para que a família experimente e aceite comportar-se ou relacionar-se de forma diversa, como se qualquer coisa diferente daquela que é conhecida (o presente e o passado) fosse ainda mais ameaçadora. Neste caso, parece-nos que teria sido indispensável trabalhar com a família as suas visões preferidas de vida (futuro) para poder, depois, equacionar o presente, como já anteriormente referimos.
Nos casos estudados, a ocorrência de singularidades e de momentos de reflexividade narrativa diminuiu na fase final da terapia, o que traduz a manutenção do funcionamento narrativo inicial, à semelhança do que se concluiu noutros trabalhos (Gonçalves et al., 2009; Gonçalves et al., 2011; Vega \& Beyebach, 2004).

A análise das sessões permitiu compreender que as dimensões dos níveis inferiores da narrativa (sobretudo do nivel um) oscilam mais ao longo das sessões, parecendo estar em consonância com o tema da sessão. Quando as sessões abordam temas menos centrados no sintoma e problemas, a família tende a veicular narrativas mais diversificadas onde os elementos são competentes e ativos, verificando-se o contrário nas sessões focalizadas no sintoma em que a conotação negativa do PI é muito evidente. Este resultado tem implicações clínicas claras pois sublinha a necessidade de sair da narrativa problema e de incluir outros temas na sessão para que a família mobilize recursos de mudança, aspeto insistentemente referido por vários autores $\mathrm{e}$ modelos terapêuticos (e.g., Avid, 2005; Burck et al., 1998; Frosh et al., 1996; White, 2007; White \& Epston, 1990). No entanto, o que este estudo permitiu perceber, nas famílias estudadas, é que a introdução de temas não problema pode não ser suficiente para gerar mudança nas histórias dominantes. Parece ser necessário, quando a família está bloqueada na dimensão tempo, espaço ou conotação moral sobre o PI, por exemplo, que se criem e amplifiquem situações para que a família possa experimentar ver-se e relacionar-se noutro enquadramento espácio-temporal e com novos papéis.

\section{Considerações Finais}

A análise exaustiva de dois casos de insucesso permitiu concluir que as famílias estudadas tendem a manter as narrativas-problema ao longo da terapia, embora possam ocorrer momentos de perturbação em dimensões específicas da narrativa (e.g. temas, conotação da narrativa e forma de relato das histórias), potenciados pela emergência de singularidades ou momentos de reflexividade narrativa. A impossibilidade de 
perturbação das histórias problema e de emergência de novas histórias parece relacionar-se com dificuldades de perturbação nos níveis superiores na narrativa (e.g., introdução do futuro e da causalidade circular; alteração da conotação moral dos elementos considerados responsáveis pelos problemas) que apoiam visões mais complexas da realidade. As dificuldades de perturbação das histórias parecem ainda relacionar-se com a utilidade funcional da narrativa dominante, sobretudo no que se refere às narrativas psicopatológicas, não apenas para as famílias mas também para o contexto relacional e social em que elas se movem, limitando assim o espaço de negociação e amplificação das versões emergentes no processo terapêutico. $\mathrm{O}$ trabalho desenvolvido permitiu perceber que os discursos que incluem singularidades ou momentos de reflexividade que se opõem à narrativa dominante ficam, nestas famílias, muito limitados ao contexto em que são proferidos. $\mathrm{O}$ "encarceramento da novidade" dificulta a construção progressiva da perceção de competência e de atividade, fundamental à ocorrência da mudança.

Algumas limitações devem ser consideradas no trabalho aqui apresentado. Os resultados e conclusões sobre a narrativa e o insucesso terapêutico devem ser cautelosamente generalizados, considerando o reduzido número de casos estudados e a sintomatologia apresentada. Importa alargar a análise a um maior número de terapias sistêmicas, com problemas diversificados, no sentido de verificar se estas conclusões são válidas noutras terapias e em casos considerados sucesso. Outros fatores, internos e externos à terapia e não considerados neste trabalho, podem ter tido influência no resultado da terapia. Referimo-nos, por exemplo, à qualidade da relação terapêutica, à adequação da metodologia de intervenção e a acontecimentos importantes exteriores à terapia.

\section{Referências}

Avid, E. (2005). Negotiating a pathological identity in the clinical dialogue: Discourse analysis of a family therapy. Psychology and Psychotherapy: Theory, Research and Practice, 78(4), 493-511. doi: 10.1348/147608305X52586.
Burck, C., Frosh, S., Strickland-Clark, L., \& Morgan, K. (1998). The process of enabling change: A study of therapist interventions in family therapy. Journal of Family Therapy, 20(3), 253-2687. doi: 10.1111/1467-6427.00086

Carr, D. (1997). Narrative and the real world: An argument for continuity. In L. Hinchman \& S. Hinchman (Eds.), Memory, identity, community: The idea of narrative in the human sciences (pp. 7-25). New York: State University of New York.

Elkaïm, M. (1990). Se você me ama, não me ame. Abordagem sistêmica em psicoterapia conjugal. São Paulo, SP: Papirus.

Elliott, J. (2005). Using narrative in social research. Qualitative and quantitative approaches. London: Sage.

Freedman, J., \& Combs, G. (2008). Narrative couple therapy. In A. Gurman (Ed.), Clinical handbook of couple therapy (pp. 229-258). New York: The Guilford Press.

Frosh, S., Burck, C., Strickland-Clark, L., \& Morgan, K. (1996). Engaging with change: A process study of family therapy. Journal of Family Therapy, 18(2), 141-161. doi: 10.1111/j.14676427.1996.tb00041.x

Gergen, K. J., Hoffman, L., \& Anderson, H. (1995). Is diagnosis a disaster: A constructionist trialogue. In F. Kaslow (Ed.), Handbook of relational diagnosis (pp. 102-118). New York: Wiley \& Sons.

Gonçalves, M. M., Matos, M., \& Santos, A. (2009). Narrative therapy and the nature of "innovative moments" in the construction of change. Journal of Constructivist Psychology, 22, 1-23.

Goncalves, M. M., Ribeiro, A. P., Stiles, W. B., Conde, T., Matos, M., Martins, C., \& Santos, A. (2011). The role of mutual in-feeding in maintaining problematic self narratives: Exploring one path to therapeutic poor outcome. Psychotherapy Research, 21(1), 27-40. doi: 10.1080/10503307.2010.507789

Hill, C. E. (1992). An overview of four measures developed to test the Hill process model: Therapist intentions, therapist response modes, client reactions and client behaviors. Journal of Counseling and Development, 70(6) 728-739. doi: 10.1177/0011000097254001

Jerónimo, A. R., Sequeira, J., \& Gaspar, M. F. (2010). A mudança narrativa em grupos de educação parental. International Journal of Developmental and Educational Psychology, 22(1), 371-379. 
Santos, C., \& Sequeira, J. (2010). Mudança narrativa na intervenção sistémica com famílias negligentes. International Journal of Developmental and Educational Psychology, 22(1), 651-660.

Sequeira, J. (2004). Caleidoscópio terapêutico. Mudança e coconstrução em terapia familiar (Dissertação de mestrado, Universidade de Coimbra, Portugal).

Sequeira, J., \& Alarcão, M. (2012a). What changes in post-modern systemic therapies? Assessing clients' narratives from good and poor outcome therapies. Manuscrito submetido para publicação.

Sequeira, J., \& Alarcão, M. (2012b). Níveis de mudança narrativa em terapia sistémica: Um olhar cibernético. Manuscrito submetido para publicação.

Sequeira, J., \& Alarcão, M. (2012c). Assessment system of narrative change. Reliability and validity studies. Manuscript submitted for publication.

Sequeira, J., \& Alarcão, M. (in press). Assessment system of narrative change. Journal of Systemic Therapies.
Sydow, K., Beher, S., Schweitze, J. S., \& Retzlaff, R. (2010). The efficacy of systemic therapy with adult patients: A meta-content analysis of 38 randomized controlled trials. Family Process, 49(4), 457-484. Retrieved from http://dx.doi. org/10.1111\%2Fj.1545-5300.2010.01334.x

Vega, M., \& Beyebach, M. (2004). Between-session change in solution-focused therapy: A replication. Journal of Systemic Therapies, 23(2), 1825. doi: 10.1521 /jsyt.23.2.18.36644

White, M. (2007). Maps of narrative practice. New York: Norton.

White, M., \& Epston, D. (1990). Narrative means to therapeutic ends. New York: Norton.

Yin, R. K. (2005). Estudo de caso: Planejamento e métodos. Porto Alegre, RS: Bookman.
Recebido: 05/08/2012

$1^{a}$ revisão: 02/11/2012

$2^{a}$ revisão: 09/01/2013

Aceite final: 25/01/2013 